\title{
GROSS MORPHOLOGY AND DIAMETER OF RENAL CORPUSCLES OF YOUNG HUMAN ADULT OF UPPER ASSAM REGION OF INDIA
}

Gautam Shyam¹, Bijoy Kumar Borah²

${ }^{1}$ Assistant Professor, Department of Anatomy, Assam Medical College, Dibrugarh, Assam, India. ${ }^{2}$ Assistant Professor, Department of Anatomy, Assam Medical College, Dibrugarh, Assam, India.

\section{ABSTRACT}

\section{BACKGROUND}

The Upper Assam region is known for different tribes and groups with distinct genetic makeup. No systematic study of human kidneys in the population of this part of India has been carried out before. The present work is an attempt to study the kidneys of young human adult population of Upper Assam region of India with the following aims and objectives.

Aims and Objectives:

1. To study the normal gross kidney morphology.

2. To study the diameter of the cortical renal corpuscles.

3. To study the differences between the right side and left side and male and female kidneys.

\section{MATERIALS AND METHODS}

Kidneys were collected from Forensic Department of a referral hospital of the region. The kidneys were cleaned of the extra tissues attached to it. The length, breadth and thickness were measured using Vernier calipers and weight was measured using electronic weighing machine. The kidney tissues were sectioned with a thickness of 5 microns and examined under low power microscope. Diameters of cortical renal corpuscles were measured using Motic software (Motic Images Plus- Version 2). The average morphological parameters and diameters of renal corpuscles were calculated and compared with the opposite side and sex using unpaired ' $\mathrm{t}$ ' test.

\section{RESULTS}

In the present study, no significant differences of morphological parameters were observed when compared with the opposite side and sex. Average diameter of cortical renal corpuscles of the left and right kidneys were found to be $120.73 \mathrm{um}$ and $121.68 \mathrm{um}$ respectively. Average diameter of the renal corpuscles in female on both left and right side were slightly less than that of the average diameter of the renal corpuscles in male. No significant differences in the diameter of cortical corpuscles were observed among the study groups.

\section{CONCLUSION}

The gross morphological measurements of kidneys observed in young human adult population of Upper Assam region were found to be less than that of the observations by other authors of other regions. The diameters of the renal corpuscles in the present study were also much less than that of the findings of other authors. This difference is probably due to difference in study population.

\section{KEY WORDS}

Cortical Corpuscles, Kidney Thickness, Average Length.

HOW TO CITE THIS ARTICLE: Shyam G, Borah BK. Gross morphology and diameter of renal corpuscles of young human adult of upper Assam region of India. J. Evolution Med. Dent. Sci. 2018;7(36):4056-4058, DOI: 10.14260/jemds/2018/905

\section{BACKGROUND}

Kidneys are situated retroperitoneally in the posterior abdominal wall. Kidneys are concerned with the maintenance of water and electrolyte balance in the body. This function of the kidney is carried out by the nephrons. Nephrons are the structural and functional units of the kidney. ${ }^{1}$ The nephron consists of a renal corpuscle concerned with filtration of

'Financial or Other Competing Interest': None.

Submission 06-09-2017, Peer Review 07-12-2017,

Acceptance 14-12-2017, Published 03-09-2018.

Corresponding Author:

Bijoy Kumar Borah,

Assistant Professor

Department of Anatomy,

Assam Medical College,

Dibrugarh-786002, Assam.

E-mail: gautamshyam74@gmail.com

DOI: $10.14260 /$ jemds $/ 2018 / 905$ plasma and renal tubules, which are concerned with electrolyte and acid-base balance. ${ }^{2}$ Renal corpuscle represents the initial part of the nephron. ${ }^{3}$ In men, nephrons are of variable sizes and diameters ranging from $150-250$ microns. ${ }^{3}$ Dunnil et $\mathrm{al}^{4}$ observed that the renal corpuscles were small rounded masses, the average diameter being $0.2 \mathrm{~mm}$.

Upper Assam region of India is known for tribes and groups with a distinct genetic makeup. On review of literature it was observed that no systematic study of kidneys including the length, breadth, thickness, weight and the diameter of the renal corpuscles has been carried out in the population of this region. So the present work was designed to study the gross morphology of kidneys and the microscopic diameter of the cortical renal corpuscles in the young adult population of the Upper Assam region. 


\section{MATERIALS AND METHODS}

The present descriptive study was carried out in the Department of Anatomy, in a referral medical college and hospital of the upper Assam region of India. Kidney specimens were collected from the Department of Forensic Medicine. Permission from the college authority and the department heads were obtained. Ethical clearance was taken before initiating the study. 60 human kidneys from 18 male and 12 female young adults were collected. Specimens were cleaned thoroughly by removing the extra tissues with the help of scalpel and forceps and then washed in normal saline. The lengths, breadths and thicknesses were measured using Vernier calipers and the weight was measured using electronic weighing machine (Sartorius). The lengths were measured between the two poles of the kidneys, breadths were measured between the medial and lateral borders at the level of the hilum and thicknesses were measured between the maximum convexities of the anterior and posterior surfaces. The specimens were fixed in $10 \%$ formalin. Slides from serial tissue sections of 5-micron thickness were made and stained by $\mathrm{H}$ and $\mathrm{E}$. The stained sections were examined under low power microscope and diameter of the cortical renal corpuscles were measured using Motic software (Motic Images Plus- Version 2). The diameters of only those corpuscles which were round or nearly round were taken into consideration to avoid possible error. 2 corpuscles were measured randomly in each of the two fields for each section in different axes. Measurements were taken in two axes perpendicular to each other for corpuscles and the mean of the two measurements were considered to be the diameter of the corpuscle.

\section{Ethical Issues}

Ethical clearance from the Institutional Ethical Committee, Human (IEC-H) was obtained before initiation of the study.

\section{Statistical Analysis}

Mean and standard deviations of all the parameters were calculated out. Statistical analysis was done using SPSSVersion 21. Unpaired ' $\mathrm{t}$ ' test was done to calculate the $\mathrm{p}$-value ( $\mathrm{p}<0.05$ was considered significant).

\section{RESULTS}

A total of 60 kidneys from 30 individuals, comprising of 18 male and 12 female adults were included in the study. The mean length, breadth and thickness of the right and left kidneys were measured as $8.92 \pm 0.47 \mathrm{~cm}$ and $8.98 \pm 0.55 \mathrm{~cm}$, $4.19 \pm 0.54 \mathrm{~cm}$ and $4.15 \pm 0.66 \mathrm{~cm}, 3.33 \pm 0.37 \mathrm{~cm}$ and $3.33 \pm$ $0.43 \mathrm{~cm}$ respectively. The mean weight for right and left kidneys were $102.77 \pm 6.76 \mathrm{gm}$ and $102.03 \pm 7.18 \mathrm{gm}$ respectively. No significant differences in morphological parameters were observed between the right and left kidneys (Table 1).

Mean diameter of the renal corpuscles were observed to be $121.68 \mu \mathrm{m}$ on right side and $120.73 \mu \mathrm{m}$ on left side (Table 2 ), which is statistically not significant.

There were no significant differences in diameters of the renal corpuscles noticed between male and female kidneys (Table 3).

\begin{tabular}{|c|c|c|c|c|c|}
\hline \multirow{2}{*}{$\begin{array}{c}\text { Parame } \\
\text { ters }\end{array}$} & \multicolumn{2}{|c|}{ Right Kidney } & \multicolumn{2}{c|}{ Left Kidney } & \\
\cline { 2 - 6 } & Range & $\begin{array}{c}\text { Mean } \\
\text { (mean } \pm \\
\text { SD) }\end{array}$ & Range & $\begin{array}{c}\text { Mean } \\
\text { (mean } \\
\pm \text { SD) }\end{array}$ & P value \\
\hline $\begin{array}{c}\text { Length } \\
\text { (cm) }\end{array}$ & $\begin{array}{c}8.13- \\
9.72\end{array}$ & $\begin{array}{c}8.92 \pm \\
0.47\end{array}$ & $\begin{array}{c}7.79- \\
9.76\end{array}$ & $\begin{array}{c}8.98 \pm \\
0.55 .\end{array}$ & 0.7504 \\
\hline $\begin{array}{c}\text { Breadth } \\
\text { (cm) }\end{array}$ & $\begin{array}{c}3.2- \\
4.82\end{array}$ & $\begin{array}{c}4.19 \pm \\
0.54\end{array}$ & $3-5.1$ & $\begin{array}{c}4.15 \pm \\
0.66\end{array}$ & 0.8572 \\
\hline $\begin{array}{c}\text { Thickness } \\
\text { (cm) }\end{array}$ & $\begin{array}{c}2.73- \\
4\end{array}$ & $\begin{array}{c}3.33 \pm \\
0.37\end{array}$ & $2.5-$ & $3.33 \pm$ & 1.0000 \\
\hline $\begin{array}{c}\text { Weight } \\
\text { (gm) }\end{array}$ & $86.53-$ & $102.77 \pm$ & $84.27-$ & $102.03 \pm$ & 0.7735 \\
\hline Table 1. Length, Breadth, Thickness and Weight of the \\
Human Kidneys
\end{tabular}

\begin{tabular}{|c|c|c|c|}
\hline \multirow{2}{*}{} & $\begin{array}{c}\text { Diameter of Renal Corpuscle } \\
\text { (Micron) }\end{array}$ & \multirow{2}{*}{ P value } \\
\cline { 2 - 3 } & R. Kidney & L. Kidney & \\
\hline Mean & 121.6875 & 120.7328 & \\
\hline SD & 4.97704 & 3.40728 & \multirow{2}{*}{0.1946} \\
\hline Minimum & 111.42 & 113.75 & \\
\hline Maximum & 134.27 & 127.21 & \\
\hline SE & .90868 & .90868 & \\
\hline \multicolumn{3}{|c|}{ Table 2. Diameter of Renal Corpuscle of Right } \\
and Left Kidneys \\
\hline
\end{tabular}

\begin{tabular}{|c|c|c|c|c|}
\hline \multirow{2}{*}{} & \multicolumn{3}{|c|}{ Diameter of Renal Corpuscle (Micron) } \\
\cline { 2 - 5 } & \multicolumn{2}{|c|}{ R. Kidney } & \multicolumn{2}{c|}{ L. Kidney } \\
\hline Male & Female & Male & Female \\
\hline Mean & 122.17 & 120.95 & 121.3128 & 119.8629 \\
\hline SD & 5.063 & 4.971 & 3.49273 & 3.22145 \\
\hline Minimum & 111.42 & 113.745 & 111.41 & 113.745 \\
\hline Maximum & 134.27 & 127.2075 & 134.26 & 125.4075 \\
\hline SE & 1.193 & 1.435 & .82325 & .92995 \\
\hline P value & \multicolumn{2}{|c|}{0.522} & \multicolumn{2}{c|}{0.261} \\
\hline
\end{tabular}

Table 3. Diameter of the Renal Corpuscle in both Sexes of Both Sides

\section{DISCUSSION}

As observed by various authors(5-10) the length of the kidneys ranged from 10 to $12.4 \mathrm{~cm}$, whereas in the present study the length ranged from 7.79 to $9.76 \mathrm{~cm}$, which was lower than the observations made by others. Interestingly, in one observation ${ }^{1}$ the author has mentioned the length as $7.5 \mathrm{~cm}$, which is somehow similar to our study.

The breadths of human kidneys in the present study ranged from 3 to $4.82 \mathrm{~cm}$, which was lower than that of the findings of previous authors where it ranged from 5 to 7.5 cm. ${ }^{(5,6,7)}$

The author observed that the thicknesses of human kidneys ranged from $2.5 \mathrm{~cm}$ to $4.2 \mathrm{~cm}$, the findings were similar to that of the observations of other authors $(5,6,7)$ where it ranged between 2.5 and $3.75 \mathrm{~cm}$.

The weights of the kidneys ranging from 84.27 to 110.87 gm in the present study which was observed to be lower than that of the observations of other authors, $(6,7)$ which ranged from $135 \mathrm{gm}$ to $170 \mathrm{gm}$.

None of the authors including the present one observed any significant difference in length, breadth, thickness and weight between right and left kidneys. Also, no significant difference in morphological parameters of kidneys was observed between male and female. 
Dunnil et $\mathrm{al}^{4}$ observed that the renal corpuscles were small rounded masses, the average diameter being $0.2 \mathrm{~mm}$. In a study conducted in Bangladesh, the mean diameter of the renal corpuscles was $159.04 \pm 8.55 \mu \mathrm{m}$ and $159.18 \pm 9.89 \mu \mathrm{m}$ on right and left kidneys respectively.(11) Mean diameter of renal corpuscles in adult human ranged from 150-250 $\mu \mathrm{m} .(3,7,12)$

In the present study, the diameters of the renal corpuscles varied from 111.41 - 134.26 microns with a mean diameter of 121.68 and 120.73 microns in right and left kidneys respectively. The diameter of renal corpuscles in the present study was much less than that of the findings of other authors.

We have observed that there is no significant difference in any of the parameters included in the study between the right-sided and left-sided kidneys and also between male and female kidneys.

From the present study three observations were made: 1 . Average length, breadth, weight of kidneys and diameter of the renal corpuscles were lower than the observations of other authors; 2 . There was no significant difference between the measurements of the right and left kidneys and between male and female kidneys; 3 . The maximum of the observations made by the present author were lower than the minimum of the observations of other authors.

As the sample size was small, further comparative study will be required to evaluate the reasons for small size of the kidneys and that of the renal corpuscles. One of the probable reasons for the smaller size of the kidneys and that of the renal corpuscles is the difference in study population.

The observations made in the present study may not be a representative of the population of the upper Assam region of India due to its small sample size, but will enrich the information on the diameter of the renal corpuscles in the population of this region.

\section{CONCLUSION}

The study was conducted in the Upper Assam region of India. The length, breadth and weight of the kidneys in the studied population were observed to be lower than the observations by other authors. The diameters of the renal corpuscles in this population were also observed to be less than the observations of other authors. Further study would give an idea about the reasons for this small size.

\section{REFERENCES}

[1] Gunsegaran JP. Textbook of histology. Atlas and practical guide. $3^{\text {rd }}$ edn. Elsevier, New Delhi 2016:pp 278.

[2] Hall E. Functional anatomy. In: Guyton and hall textbook of medical physiology. A south Asian Edition. New Delhi; Elsevier, 2013:pp 462.

[3] Bulger RE, Dobyan DC. Recent advances in renal morphology. Annu Rev Physiol 1982;44:147-79.

[4] Dunnill MS, Halley W. Some observations on the quantitative anatomy of the kidney. J Pathol 1973;110(2):113-21.

[5] Romanes GJ. The abdominal cavity. In: Cunninghams manual of practical anatomy. 15th edn. New York: Oxford Medical Publication, 2006:pp 167.

[6] Tauchi H, Tsuboi K, Okutomi J. Age changes in the human kidney of the different races. Gerontologia 1971;17(2):87-97.

[7] Standring S. Kidney and ureter. In: Gray's anatomy: the anatomical basis of clinical practice. 39th edn. Churchill Livingstone, London; Elsevier, 2008:pp 1225.

[8] Miletic D, Fuckar Z, Sustic A, et al. Sonographic measurement of absolute and relative renal length in adults. J Clin Ultrasound 1998;26(4):185-9.

[9] Glodny B, Unterholzner V, Taferner B, et al. Normal kidney size and its influencing factors- a 64- slice MDCT study of 1.040 asymptomatic patients. BMC Urol 2009;9:19.

[10] Hammad L. A sonographic study of kidney dimensions in Saudis university students. Pak J Med Sci 2012;28(3):395-9.

[11] Banik S, Aktar F. Diameter of renal corpuscles of Bangladeshi people in different age group. Journal of Enam Medical College 2014;4(1).

[12] Moore L, Williams R, Staples A. Glomerular dimensions in children under 16 years of age. J Pathol 1993;171(2):145-50. 